\title{
Effect of a Preliminary Aging Treatment on the Oxidation Kinetic at High Temperature for a Cobalt-Based Alloy Strengthened by Tantalum Carbides
}

\author{
Patrice Berthod*, Lionel Aranda and Cédric Heil \\ Institut Jean Lamour (UMR CNRS 7198), Department 2 - Chemistry and Physics of Solids and Surfaces, Nancy - \\ University, B.P. 70239, 54506 Vandoeuvre-lès-Nancy, France
}

\begin{abstract}
The purpose of this work is to examine if the behavior of refractory alloys in oxidation at high temperature can be influenced by the modification of the interdendritic carbides morphology due to a preliminary aging treatment at high temperature. A cobalt-based alloy strengthened by tantalum carbides was first exposed to $1200^{\circ} \mathrm{C}$ over a period of 100 hours, and characterized in high temperature oxidation, with samples cut in the middle of the alloy. Thermogravimetry runs were performed in air at 1000,1100 and $1200^{\circ} \mathrm{C}$ during 50 hours, and the results were analyzed in order to specify the rates of transient oxidation, of parabolic oxidation and of chromia volatilization. The oxidized samples were metallographically examined. The fragmentation of the $\mathrm{TaC}$ carbides induced by the aging treatment tends to accelerate the oxidation kinetics in general, with higher values of parabolic and volatilization constants especially at $1200^{\circ} \mathrm{C}$.
\end{abstract}

Keywords: Cobalt alloy, tantalum carbides, aging, high temperature oxidation, chromia volatilization.

\section{INTRODUCTION}

In service, a long exposure at very high temperature may induce significant changes for the microstructure of superalloys. Among the microstructure modifications often observed for industrial superalloys (used under mechanical stresses or not) one can cite coarsened grains, morphology changes for carbides [1], the rafting structure of gamma prime in Al-containing nickel-based superalloys [2], the fragmentation of $\mathrm{TaC}$ carbide fibers in the directionally solidified Co-based superalloys [3] or of interdendritic eutectic MC-carbides in cast alloys and superalloys [2, 4-6]. In situation of high temperature oxidation by gases or corrosion by molten salts, such microstructure modifications of intragranular or intergranular reinforcing particles are probably able to influence the diffusion of species involved in these phenomena since, among these species, there are often very oxidable elements which were initially present in the hardening particles, such as Al in the gamma prime precipitates or tantalum in carbides. In the latter case and for alloys elaborated by a foundry way, this can be enhanced by the fact that carbides are present mainly in grain boundaries which are well known to be preferable diffusion paths [7].

The aim of this work is to study how a preliminary exposure to high temperature, applied for a certain period of time, can influence the kinetic of oxidation at high temperature of a chromia-forming refractory alloy based on cobalt and mechanically strengthened by interdendritic tantalum carbides, as a result of a morphology change of the latter.

*Address correspondence to this author at the Institut Jean Lamour (UMR CNRS 7198), Department 2 - Chemistry and Physics of Solids and Surfaces, Nancy - University, B.P. 70239, 54506 Vandoeuvre-lès-Nancy, France; E-mail: Patrice.Berthod@1csm.uhp-nancy.fr

\section{MATERIALS AND METHODOLOGY}

\section{Synthesis of the Samples and Thermogravimetry Runs}

The studied alloy is based on cobalt. Its targeted contents in the different elements are $52 \mathrm{wt} . \%$ of cobalt, $30 \mathrm{wt} . \%$ of chromium (high enough for allowing a chromia-forming behavior for several tens or hundreds hours, a duration which depends on both the temperature and the corrosive environment), 10wt.\% of nickel for stabilizing the Face Centered Cubic structure for matrix down to sufficiently low temperatures, $0.5 \mathrm{wt} . \%$ of carbon for forming strengthening carbides, and $7.5 \mathrm{wt} . \%$ of tantalum to promote the formation of $\mathrm{TaC}$ carbides which are among the most stable ones at very high temperatures. Three $100 \mathrm{~g}$-ingots were cast in a (HF) induction furnace, under inert atmosphere (several hundreds mbars of pure argon), from pure elements (purity higher than $99 \%$ in mass): $\mathrm{Co}, \mathrm{Ni}, \mathrm{Cr}$ and $\mathrm{Ta}$ supplied by Alfa Aesar, and $\mathrm{C}$ as graphite. Fusion and solidification were performed in the water-cooled copper crucible of the HF induction furnace (CELES).

The three ingots were cut to cubes (dimensions: about 15 $\mathrm{mm} \times 15 \mathrm{~mm} \times 15 \mathrm{~mm}$ ). A first one was heated at $20 \mathrm{~K} \mathrm{~min}^{-1}$ from room temperature to $1200^{\circ} \mathrm{C}$, maintained at this temperature for 5 hours and air cooled thereafter. For the second and third ones the difference was the duration of the isothermal soaking before air cooling: 25 hours and 100 hours. Three parallelepipeds (about $10 \mathrm{~mm} \times 10 \mathrm{~mm} \times 3$ $\mathrm{mm}$ ), destined to the thermogravimetry tests, were cut in the centre of each cube, out of the external zone of the cube which was affected by oxidation during the previous treatment at $1200^{\circ} \mathrm{C}$. The parallelepipeds were polished with $\mathrm{SiC}$ paper grade 1200, with smoothing of edges. Thermogravimetry runs were performed using a Setaram thermobalance (TAG 1750 Simultaneous symmetrical thermoanalyser), in a flow of $11 \mathrm{~h}^{-1}$ of synthetic air $\left\{80 \% \mathrm{~N}_{2}\right.$ $\left.-20 \% \mathrm{O}_{2}\right\}$ from the Air Liquide company. Heating rates and 
cooling rates were respectively $20 \mathrm{~K} \mathrm{~min}^{-1}$ and $-10 \mathrm{~K} \mathrm{~min}^{-1}$ and the temperatures of the $50 \mathrm{~h}-$ dwells were 1000,1100 and $1200{ }^{\circ} \mathrm{C}$.

\section{Numerical Treatment of the Mass Gain Measurements}

Oxidation usually starts during the heating with nucleation and growth of a discontinuous oxide scale, which leads to a first mass gain. During a very short first part of the isothermal dwell, oxidation remains transient and the mass gain generally obeys a linear kinetic which leads to a second mass gain. This linear kinetic, of the $\left\{\mathrm{d} m=K_{l} \times d t\right\}$-type in which $\mathrm{m}$ is the mass gain per surface unit (in $\mathrm{g} \mathrm{cm}^{-2}$ ) and $\mathrm{K}_{1}$ is the linear oxidation constant (in $\mathrm{g} \mathrm{cm}^{-2} \mathrm{~s}^{-1}$ ), is usually short (between 5 and 15 minutes in the case of the alloys studied here) and is thereafter replaced by the Wagner's [8] parabolic oxidation. In order to correctly determine the parabolic kinetic, it is necessary to take into account the total mass gain previously achieved by transient oxidation before. The second part of the mass gain due to the transient oxidation (isothermal) can be directly measured by the thermo-balance. In contrast the first part of the transient mass gain (during heating) cannot be directly measured because of the variation of the Archimede's thrust accompanying the increase in temperature. However, it is possible to deduce it from the three values of the linear constant $K_{1}(T)$, which represent the linear isothermal kinetic of the isothermal part of the transient oxidation at 1000,1100 and $1200^{\circ} \mathrm{C}$, since this constant can be considered as an exponential function of the reciprocal absolute temperature. Thus, the exploitation of each file of mass gain measurements began by the determination of the values of the linear constant $\mathrm{K}_{1}$ for 1000,1100 and $1200^{\circ} \mathrm{C}$. After having verified that $\mathrm{K}_{1}$ obeys an Arrhenius law, it was possible to estimate the mass gain obtained during the whole heating period before the isothermal dwell (procedure entirely described in an earlier work [9]). This first mass gain was then added to the isothermal mass gain obtained during the second part of the transient oxidation to know the value $\mathrm{m}_{0}$ of the total mass gain achieved by transient oxidation.

The analysis of the mass gain measurements was performed in order to determine both the parabolic constant $\mathrm{K}_{\mathrm{p}}$ and the volatilization constant $\mathrm{K}_{\mathrm{v}}$, for a better characterization of the oxidation rate. Indeed, above $1000^{\circ} \mathrm{C}$ a part of the external chromia $\left(\mathrm{Cr}_{2}^{\mathrm{III}} \mathrm{O}_{3}\right)$ scale may be more or less rapidly re-oxidized another time in a new oxide $\left(\mathrm{Cr}^{\mathrm{VI}} \mathrm{O}_{3}\right)$ gaseous at these temperatures. Taking into account this phenomenon may avoid any minimization of the parabolic oxidation kinetic. The mass gain files were exploited according to the equation: $m \cdot \frac{d m}{d t}=K_{p}-K_{v} \cdot m$, in which $\mathrm{m}$ is the mass gain per unit aera. The variation of $m \cdot \frac{d m}{d t}$ versus $-m$ may lead to a straight line, for which the ordinate at the origin is equal to $\mathrm{K}_{\mathrm{p}}$ and the slope is equal to $\mathrm{K}_{\mathrm{v}}$. Thus, values of $K_{p}$ and $K_{v}$ can be readily determined. However, the little lack of precision of the thermobalance can lead to more or less dispersed values for $m \cdot \frac{d m}{d t}$, because of stability problem concerning the $\frac{d m}{d t}$ values. Indeed, the difference between two successive values of $\mathrm{m}$ (the second one recorded only 40 seconds after the first one) is not significant enough to lead to a correct value of the mass gain rate. Here it was preferred to estimate this derived number by considering the regression coefficient calculated from eleven successive couples $(t, m)$ surrounding the considered time (then there is a new time step which is ten times greater than the initial measure time step). This allows having an average value over 400 seconds which better represents the real mass gain rate.

\section{Metallographic Observations}

After cooling to room temperature, the oxidized samples were embedded in resin, cut, polished using $\mathrm{SiC}$ papers (grades from 120 to 1200 ), then by alumina $1 \mu \mathrm{m}$-particles. A Scanning Electron Microscope (SEM, type: Philips XL30) was used in Back Scattered Electron mode (BSE) with an acceleration voltage of $20 \mathrm{kV}$ for metallographic observations.

\section{RESULTS}

\section{Microstructure Observations}

The chemical composition of the alloy is well respected since measurements performed with a Cameca SX100 microprobe led to $30 \pm 1.0 \mathrm{wt} . \% \mathrm{Cr}, \quad 10 \pm 0.3 \mathrm{wt} . \% \mathrm{Ni}$ and $7.6 \pm 0.5 \mathrm{wt} . \% \mathrm{Ta}$, while the carbon content, which cannot be measured by this technique, is obviously at the $0.5 \mathrm{wt} . \%$ value as shown by the density of carbides. In addition previous elaborations of such alloys with the same procedure always led to well respected values for $\mathrm{C}$ as verified earlier by sparkling spectrometry.

The microstructure of the alloy is composed of a dendritic matrix of cobalt containing a part of the other elements in solid solution (or entirely in the case of nickel), and tantalum carbides. The latter are mainly interdendritic forming a eutectic compound with the matrix, but there are also some fine carbides dispersed in the dendritic matrix. After aging at 5 (Fig. 1A), 25 (Fig. 1B) or 100 hours (Fig. 1C), one can observe a fragmentation of interdendritic $\mathrm{TaC}$ carbides after 25 and 100 hours, more enhanced than after 5 hours only. Most of the initial "script"-shaped carbides, which existed in the as-cast condition, have then become numerous small and round carbides. This is illustrated by enlarged (x2) views in Fig. (1A) (eutectic TaC carbides still with a "script" form) and Fig. (1C) ( $\mathrm{TaC}$ become fragmented because of interfacial energy reduction) in the top right corners of the main micrographs.

\section{Thermogravimetry}

The mass gain curves obtained at $1000^{\circ} \mathrm{C}$ (Fig. 2A) are all affected by problems of oxide detachment. Indeed, they show either one great step (alloy aged during $25 \mathrm{~h}$ or $100 \mathrm{~h}$ ) or several smaller steps (alloy aged during only $5 \mathrm{~h}$ ), which are due to a rapid new oxidation of the part of surface denuded because of local detachment of the protective oxide layer. For the two highest temperatures no jumps are visible, but the mass gain rate is of course faster. Despite the irregularity of the curves at $1000^{\circ} \mathrm{C}$ and their apparent differences of 

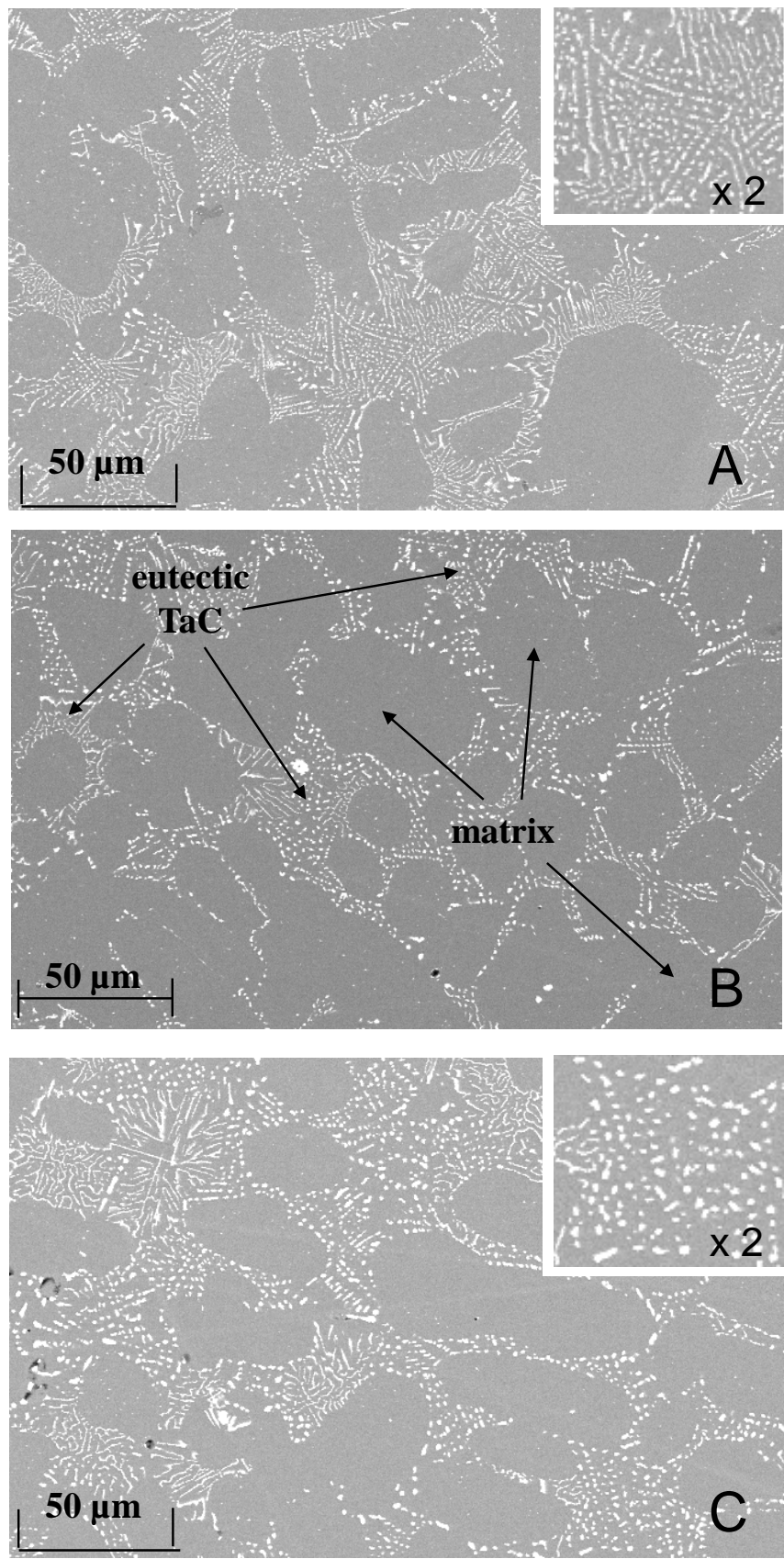

Fig. (1). Microstructures of the studied cobalt-based alloy after aging treatment at $1200^{\circ} \mathrm{C}$ during 5 hours $\left(\mathbf{A}^{*}\right), 25$ hours $(\mathbf{B})$ or 100 hours $\left(\mathbf{C}^{* *}\right)$ (SEM micrographs taken in BSE mode). *: with (x2) zoomed view for better distinguishing the initial state of the carbides, not yet really affected after only $5 \mathrm{~h} . * *$ : with (x2) zoomed view for better distinguishing the fragmentation of the carbides after $100 \mathrm{~h}$.

position, the mass gain kinetic at this temperature seems to be almost the same for the three aged states. Indeed, the last parts of these curves are almost parallel to one another. This is obviously also true at $1100^{\circ} \mathrm{C}$ (Fig. 2B) since the three curves are almost perfectly superposed, but real differences begin appearing for the mass gain curves realized at $1200^{\circ} \mathrm{C}$ (Fig. 2C): the 100h-aged alloy obviously oxidized faster than the $5 \mathrm{~h}$-aged and the $25 \mathrm{~h}$-aged alloys.
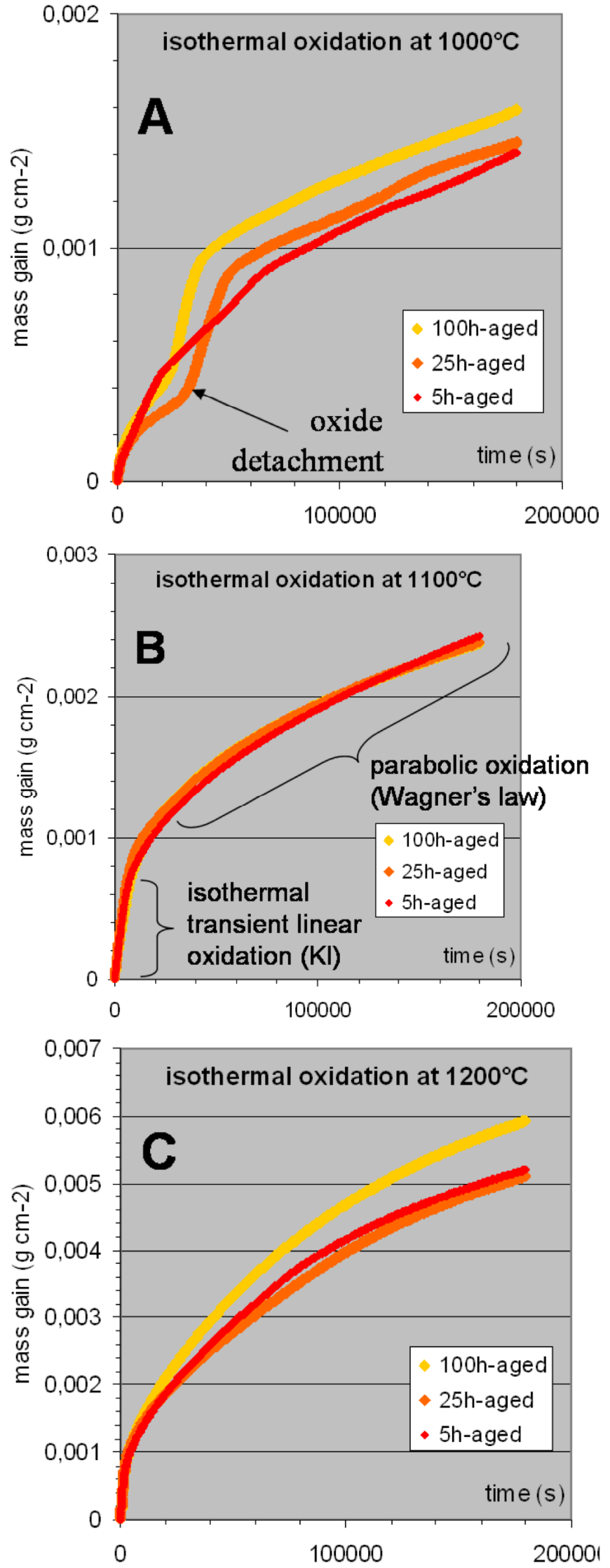

Fig. (2). Mass gain curves for the three aged states, at $1000^{\circ} \mathrm{C}(\mathbf{A})$, $1100^{\circ} \mathrm{C}(\mathbf{B})$ and $1200^{\circ} \mathrm{C}(\mathbf{C})$. 
When plotted according to the $m \times \frac{d m}{d t}=K_{p}-K_{v} \times m$ scheme, the mass gain curves generally present a more or less extended linear part on the left, after one or several peaks due to either a step of mass gain induced by a local oxide detachment, or simply by the transition from the isothermal linear oxidation to the parabolic one (Fig. 3A). This allowed specifying the two kinetic oxidation constants $\mathrm{K}_{\mathrm{p}}$ and $\mathrm{K}_{\mathrm{v}}$ the values of which were tested by plotting a mathematical curve and comparing the latter with the experimental mass gain curve. The values obtained for the parabolic constant and the constant of mass loss rate due to chromia volatilization, were generally tested with success: either the mathematical curve was almost superposed to the experimental one (Fig. 3B), or its last part was parallel to the last part of the experimental curve (e.g. in case of step due to oxide detachment).
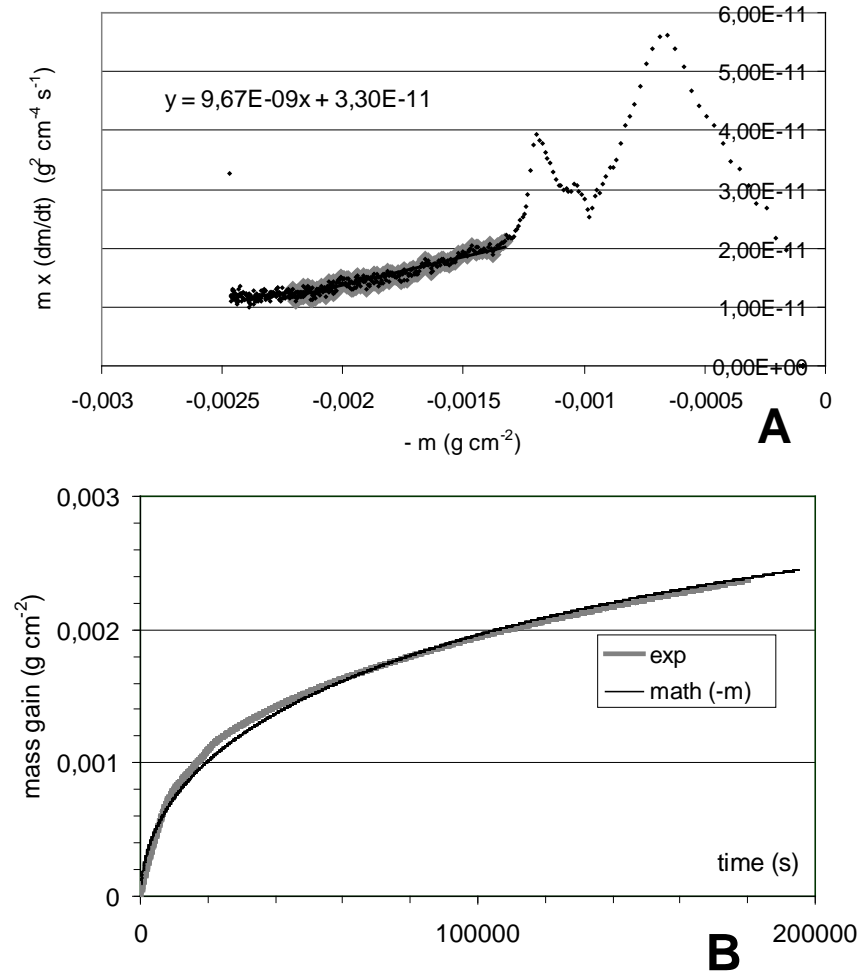

Fig. (3). Example of thermogravimetry results (100h-aged alloy oxidized at $1100^{\circ} \mathrm{C}$ ) plotted according to the equation $m \times \frac{d m}{d t}=K_{p}-K_{v} \times m \quad$ (A) and comparison between the experimental curve and the one built with $\mathrm{K}_{\mathrm{p}}=33 \times 10^{-12} \mathrm{~g}^{2} \mathrm{~cm}^{-4} \mathrm{~s}^{-1}$ and $\mathrm{K}_{\mathrm{v}}=96.7 \times 10^{-10} \mathrm{~g} \mathrm{~cm}^{-2} \mathrm{~s}^{-1}$ previously determined (B).

\section{Study of the Kinetic Constants}

The linear transient constant $\mathrm{K}_{1}$, was assessed either by the slope of the linear part at the beginning of the isothermal mass gain curve, or by the slope of the tangent, at the origin, to this isothermal curve when this one was very early parabolic. This constant logically increases when the test temperature increases but there is no systematic dependence on the aging duration (Fig. 4A). Plotting its Neperian logarithm versus the reciprocal absolute temperature led to a dependence which was never very linear (Fig. 5A).
Nevertheless, this was used to estimate the mass gain achieved during heating.
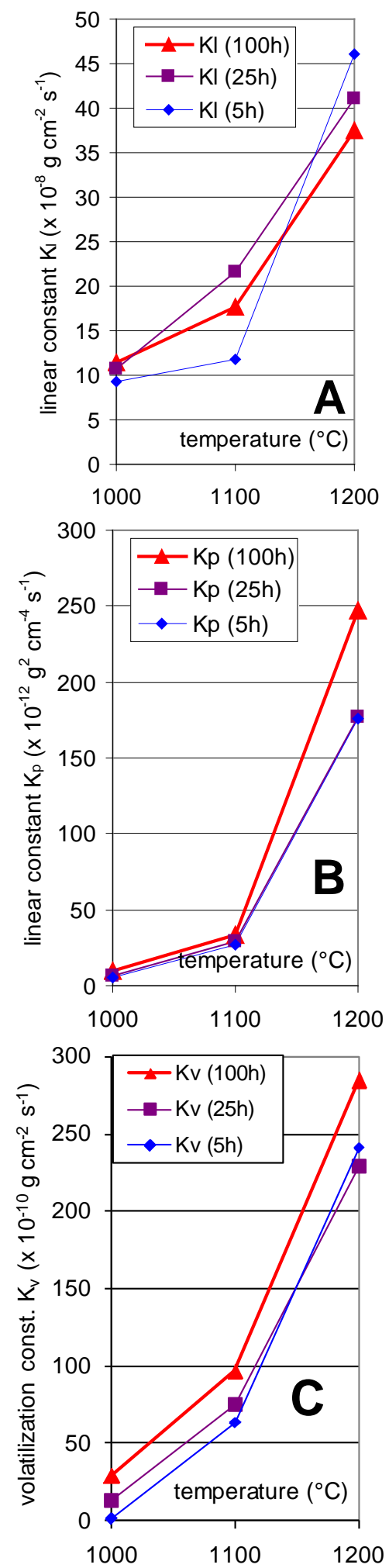

Fig. (4). Evolution of the linear constant $\mathrm{K}_{1}(\mathbf{A})$, of the parabolic constant $\mathrm{K}_{\mathrm{p}}$ (B) and the volatilization constant $\mathrm{K}_{\mathrm{v}}$ (C) with temperature, for the three aged states.

The determination of both $K_{p}$ and $K_{v}$ led to more interesting results. Indeed, the parabolic constant is almost 

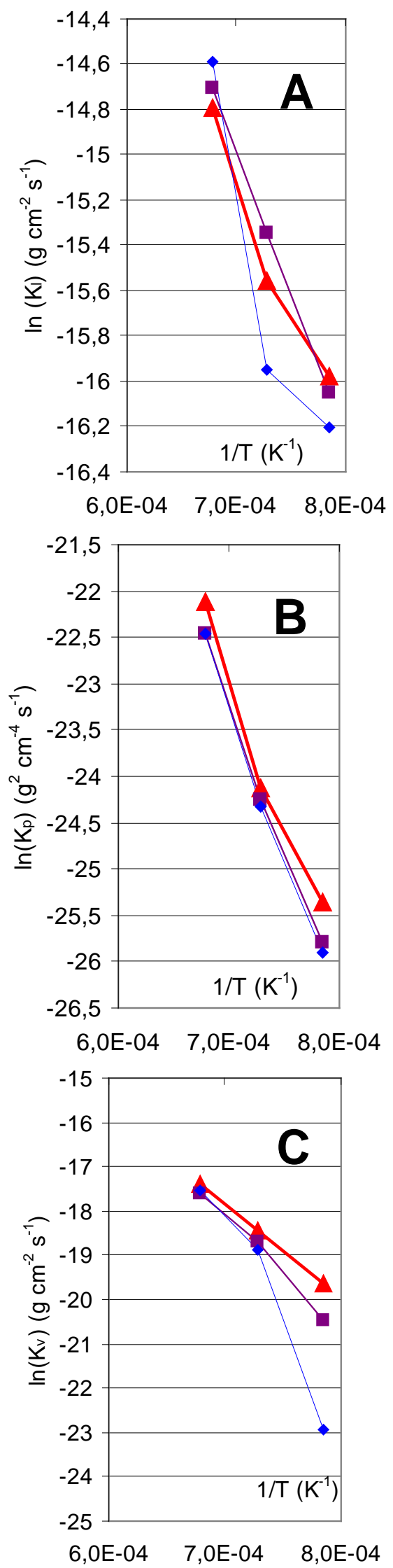

Fig. (5). Plot of the linear constant $\mathrm{K}_{1}$ (A), of the parabolic constant $\mathrm{K}_{\mathrm{p}}$ (B) and the volatilization constant $\mathrm{K}_{\mathrm{v}}$ (C) for the three aged states, in Arrhenius representation. the same for the three aged states (Fig. 4B) for the two lowest temperatures, but at $1200^{\circ} \mathrm{C}$ it is significantly higher for the $100 \mathrm{~h}$-aged state than for the two others (which both led to the same values). There is a more systematic difference for the volatilization constant (Fig. 4C) since, for all temperatures of thermogravimetry test, $\mathrm{K}_{\mathrm{v}}$, which logically increases with temperature as $\mathrm{K}_{\mathrm{p}}$, also increases with the aging duration. The difference which already exists between $5 \mathrm{~h}$ and $25 \mathrm{~h}$, is enhanced when the comparison is done between $25 \mathrm{~h}$ and $100 \mathrm{~h}$. When represented in an Arrhenius plot, the alignment is better for a short aging ( $5 \mathrm{~h}$ or $25 \mathrm{~h}$ ) than for a too long one $(100 \mathrm{~h})$ in the case of $K_{p}$ (Fig. 5B) while the alignment is generally good for $\mathrm{K}_{\mathrm{v}}$, except for the $5 \mathrm{~h}$-aged alloy oxidized at $1000^{\circ} \mathrm{C}$ (Fig. 5C). The activation energies that can be deduced from these representations are around $260 \mathrm{~kJ} \mathrm{~mol}^{-1}$ for Kp for all aged states (more precisely 267, 259 and $251 \mathrm{~kJ} \mathrm{~mol}^{-1}$ for respectively $5 \mathrm{~h}, 25 \mathrm{~h}$ and $100 \mathrm{~h}$ ), showing that the oxidation kinetic is governed by the outward diffusion of cations through the external oxide scale. The activation energy for chromia volatilization is a little more dispersed 226 and $176 \mathrm{~kJ}$ $\mathrm{mol}^{-1}$ for $25 \mathrm{~h}$ and $100 \mathrm{~h}$ (no value for $5 \mathrm{~h}$ since the three points are not really aligned).

\section{Surface States of the Oxidized Samples}

The samples were all covered by a continuous layer of chromia $\left(\mathrm{Cr}_{2} \mathrm{O}_{3}\right)$ more or less mixed with films of oxide of both chromium and tantalum $\left(\mathrm{CrTaO}_{4}\right)$, but unfortunately cooling induced spallation and only some parts of the oxide remained on the surface. Internal oxidation also occurred, with appearance of $\mathrm{CrTaO}_{4}$ at grain boundaries near the surface. After oxidation at $1000^{\circ} \mathrm{C}$ during 50 hours (Fig. 6), the chromia layer was relatively thin (about $5 \mu \mathrm{m}$ thick) and in some places on a sample one can see precipitation of new carbides (acicular chromium carbides) in a zone separating the outer carbide-free zone (in which primary carbides disappeared because of oxidation) and the inner bulk, while no such precipitated carbides are visible in other locations on the same sample. This phenomenon was earlier explained by an inward diffusion of carbon atoms quitting the carbides disappearing because of oxidation [10]. The phenomenon of precipitation of new carbides did not occur at $1100^{\circ} \mathrm{C}$ (Fig. 7) or $1200^{\circ} \mathrm{C}$ (Fig. 8), while the average thickness of chromia (about $20 \mu \mathrm{m}$ for $1100^{\circ} \mathrm{C}$ and $30 \mu \mathrm{m}$ for $1200^{\circ} \mathrm{C}$ ), the depth of

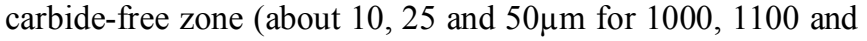
$1200^{\circ} \mathrm{C}$, respectively), and the quantity of internal oxide increase with the isothermal temperature, with seemingly, for $1200^{\circ} \mathrm{C}$, a greater quantity of external chromia and internal oxides deeper in the alloy for the 100h-aged sample than for the $25 \mathrm{~h}$-aged and $5 \mathrm{~h}$-aged ones.

\section{DISCUSSION}

The exposure to a high temperature such as $1200^{\circ} \mathrm{C}$ may induce microstructure modifications for cast carbidesstrengthened cobalt-base alloys, even if these carbides are among the most stable ones. Here the interdendritic tantalum carbides are affected by a fragmentation phenomenon which increases with the aging duration at $1200^{\circ} \mathrm{C}$. The different morphologies obtained for the interdendritic carbides because of these three different aging treatments may influence the diffusion phenomena involved by high temperature oxidation. At $1000^{\circ} \mathrm{C}$ or $1100^{\circ} \mathrm{C}$ during 50 


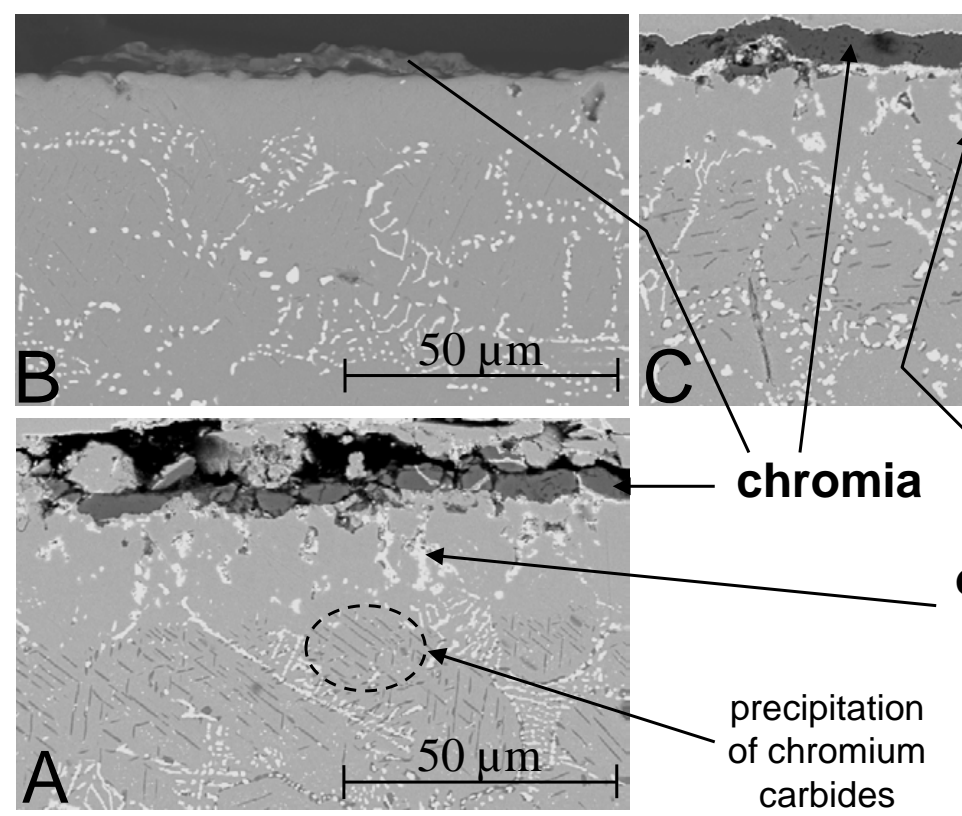

Fig. (6). Surface states after oxidation at $1000^{\circ} \mathrm{C}$ of the 5 h-aged (A), 25 h-aged (B) and 100h-aged (C) alloys.

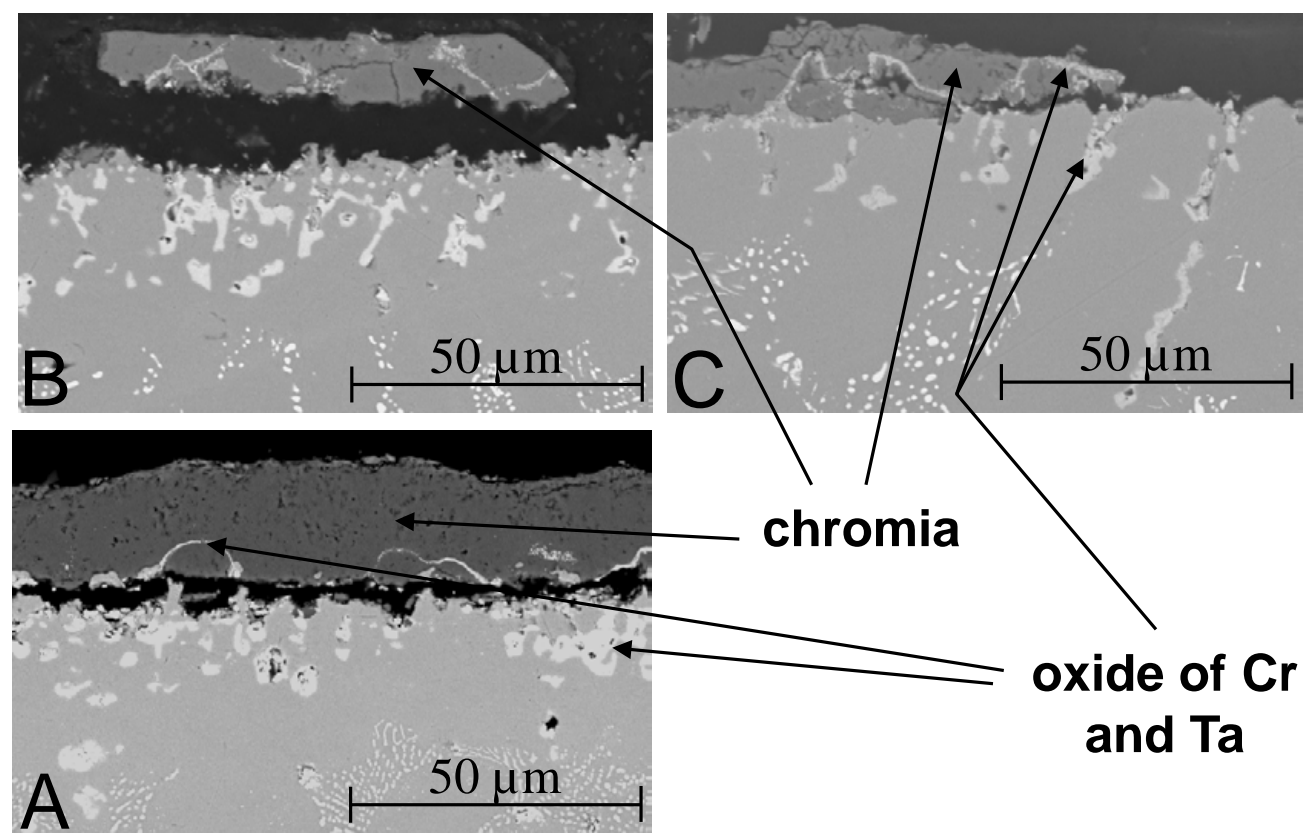

Fig. (7). Surface states after oxidation at $1100^{\circ} \mathrm{C}$ of the 5 h-aged (A), 25h-aged (B) and 100h-aged (C) alloys.

hours (a relatively short duration) the sub-surface affected by oxidation was seemingly not deep enough to permit revealing such differences of diffusion with visible consequences for the oxidation kinetic. In contrast, at $1200^{\circ} \mathrm{C}$, for which the depth affected by oxidation is great enough by comparison to the microstructural typical size, a significant difference appears for the oxidation kinetic, between on the one hand the short durations of preliminary aging (5 and 25 hours) and on the other hand the aging during 100 hours. These differences concern not only the parabolic oxidation but also the volatilization rate of chromia. It is possible that the reason of the faster oxidation at $1200^{\circ} \mathrm{C}$ of the $100 \mathrm{~h}$-aged alloy is the greater part of internal oxide of both chromium and tantalum, probably because a more difficult diffusion of Ta atoms towards the external surface because of the fragmentation of the carbides. Then oxidation takes place in an area more extended in depth, with consequently a slightly faster parabolic kinetic and a higher value for $K_{p}$. If a greater part of tantalum is oxidized internally, this also leads to less oxide of tantalum in the external oxide scale. Since it was earlier observed that the presence of $\mathrm{Ta}$ oxide in the external scale limited chromia volatilization [11], this may here lower the effect of protection for chromia against volatilization and then lead to a higher value for $\mathrm{K}_{\mathrm{v}}$. Effectively it is what was observed here.

It can be also noticed that the values of parabolic constant (5 to 10,27 to 33 and 175 to $250 \times 10^{-12} \mathrm{~g}^{2} \mathrm{~cm}^{-4} \mathrm{~s}^{-1}$ at 1000,1100 and $1200^{\circ} \mathrm{C}$, respectively) are somewhat higher (but consistent) to $\mathrm{K}_{\mathrm{p}}$ values obtained for similar 


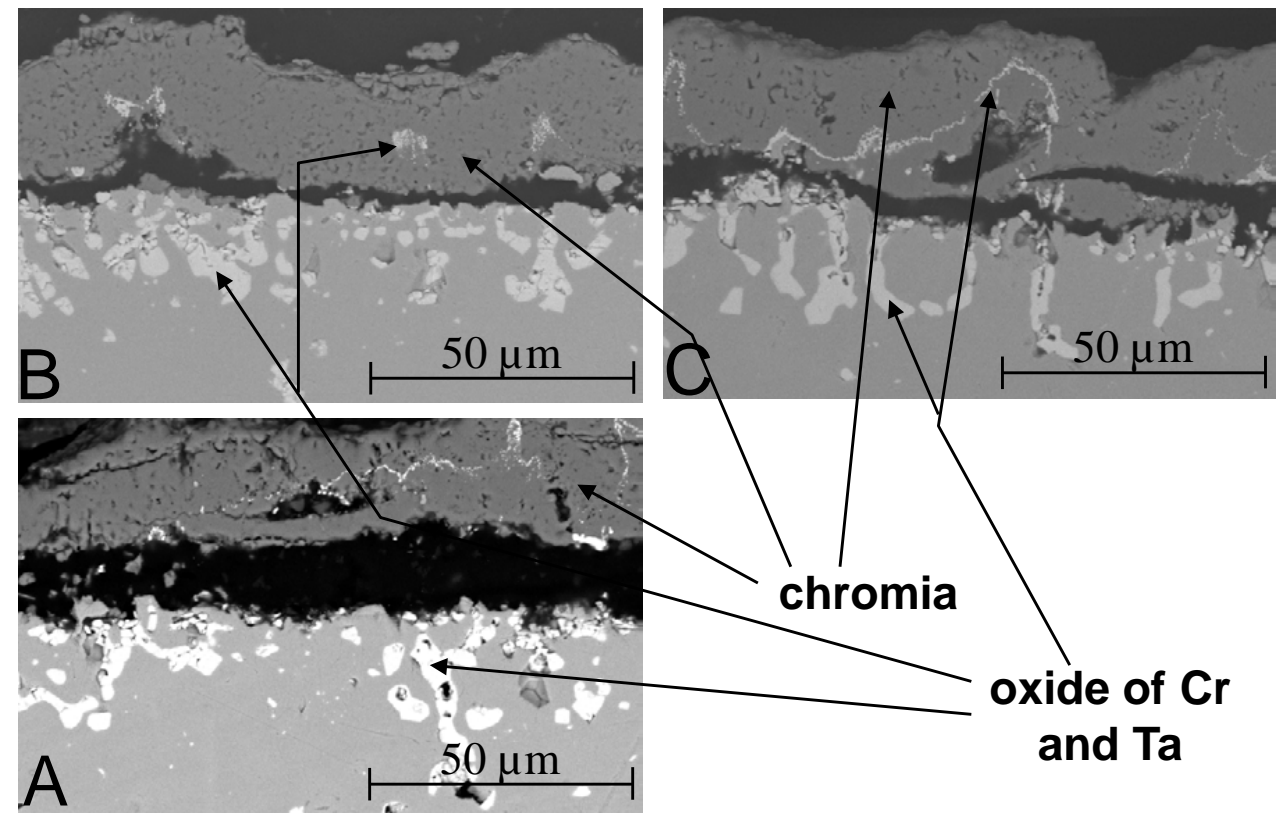

Fig. (8). Surface states after oxidation at $1200^{\circ} \mathrm{C}$ of the 5 h-aged (A), $25 \mathrm{~h}$-aged (B) and 100h-aged (C) alloys.

alloys with less tantalum in a previous work [12] and the values of volatilization constant $(<30,60$ to 100 and 240 to $300 \times 10^{-10} \mathrm{~g} \mathrm{~cm}^{-2} \mathrm{~s}^{-1}$ at 1000,1100 and $1200^{\circ} \mathrm{C}$, respectively) are also consistent with values obtained for chromia in earlier studies $[13,14]$.

\section{CONCLUSION}

The morphologies of interdendritic carbides can have a real influence on the behaviour of carbides-strengthened alloys in oxidation at high temperature. This was observed in this study for both a sufficient fragmentation of the $\mathrm{TaC}$ reinforcing a cobalt-based alloy, and a temperature of oxidation high enough to enhance the effect of such modification on diffusion of the species involved in the oxidation phenomenon. More precisely, for these conditions favoring such an influence, carbide fragmentation, which necessarily takes place on long times in service, seems accelerating the oxidation rate. Thus, promoting a carbide fragmentation, which already mechanically weakens alloys, is not a way for improving their resistance against high temperature oxidation.

\section{ACKNOWLEDGEMENT}

The authors thank the Common Service of Microscopy and Microanalyses of the Faculty of Science and Techniques of the University Henri Poincaré Nancy 1.

\section{REFERENCES}

[1] Bradley EF, Ed. Superalloys: A Technical Guide. Russell Township, Ohio: ASM International 1988.

[2] Sims CT, Hagel WC. The Superalloys. New York: John Wiley \& Sons 1972.
[3] Stohr JF. Thermal stability of directionally solidified metal-carbide composites. Ann Chim 1980; 5: 226-41.

[4] Berthod P, Michon S, Aranda L, Mathieu S, Gachon JC. Experimental and thermodynamic study of the microstructure evolution in cobalt-base superalloys at high temperature. Calphad 2003; 27: 353-9.

[5] Berthod P, Aranda L, Vébert C, Michon S. Experimental and thermodynamic study of the high temperature microstructure of tantalum-containing nickel-based alloys. Calphad 2004; 28: 15966.

[6] Berthod P, Hamini Y, Aranda L, Héricher L. Experimental and thermodynamic study of tantalum-containing iron-based alloys reinforced by carbides: Part I - Case of (Fe,Cr)-based ferritic steels. Calphad 2007; 31: 351-60.

[7] Kofstad P. High Temperature Corrosion. London: Elsevier applied science 1988; pp. 382-5.

[8] Wagner C. The theory of the warm-up process. Z Phys Chem 1933; 21(1/2): 25-41

[9] Berthod P. Kinetics of high temperature oxidation and chromia volatilization for a binary Ni-Cr alloy. Oxid Met 2005; 64(3/4): 235-52.

[10] Berthod P, Vébert C, Aranda L, Podor R, Rapin C. Study of carbides transformations during high-temperature oxidation of nickel-base superalloys. Oxid Met 2005; 63(1/2): 57-72.

[11] Berthod P, Aranda L, Vébert C. Etude cinétique de l'oxydation à haute temperature et de la volatilisation de la chromine pour des superalliages de fonderie renforcés par carbures. Partie I: cas d'alliages à base de nickel contenant du tantale. Ann Chim Sci Mat 2006; 31(2): 213-35.

[12] Berthod P, Raude S, Chiaravalle A. Etude cinétique de l'oxydation à haute temperature et de la volatilisation de la chromine pour des superalliages de fonderie renforcés par carbures. Partie II: cas de superalliages a base de cobalt et influence de la finesse dendritique. Ann Chim Sci Mat 2006; 31(2): 237-58.

[13] Hagel WC. Factors controlling the high-temperature oxidation of chromium. ASM Trans Q 1963; 56(3): 583-99.

[14] Stearns CA, Kohl FJ, Fryburg GC. Oxidative vaporization kinetics of chromium(III) oxide in oxygen from 1000 to 1300 . deg. J Electrochem Soc 1974; 121(7): 945-51.

This is an open access article licensed under the terms of the Creative Commons Attribution Non-Commercial License (http://creativecommons.org/licenses/by$\mathrm{nc} / 3.0 /$ ) which permits unrestricted, non-commercial use, distribution and reproduction in any medium, provided the work is properly cited. 